Volume 9, No.1.2, 2020

International Journal of Advanced Trends in Computer Science and Engineering

Available Online at http://www.warse.org/IJATCSE/static/pdf/file/ijatcse0691.22020.pdf

https://doi.org/10.30534/ijatcse/2020/0691.22020

\title{
A Review on Electricity tracing techniques for losses charge allocation in restructured power market
}

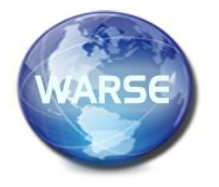

\author{
Zulkiffli Abdul Hamid ${ }^{1}$, Ismail Musirin' ${ }^{2}$, Muhammad Murtadha Othman ${ }^{3}$, Zuhaila Mat $\operatorname{Yasin}^{4}$ \\ Faculty of Electrical Engineering \\ Universiti Teknologi MARA \\ 40450 Shah Alam \\ Selangor MALAYSIA \\ zulfkeuitm@gmail.com ${ }^{1}$, ismailbm1@gmail.com ${ }^{2}$
}

\begin{abstract}
This paper presents an introductory survey on various methods of transmission and losses charge allocation. It starts with the explanation on the key components involved in deregulated power market. Starting with an overview, the basic elements of the market (structure, model and operation) are explained to give an introduction for better understanding of deregulation concept. Later, readers are presented with three most applied methods (traditional based, conventional tracing and computational intelligence) for losses charge allocation, categorized based on their principles and formulation techniques. The strengths and weaknesses of the three are critically reviewed and summarized. Researchers (or new readers interested in electricity deregulation) may decide a proper choice of method based on the findings presented here.
\end{abstract}

Key words : Electricity, allocation, market

\section{INTRODUCTION}

In contrast to vertically integrated system, a deregulated environment comprises of participants working together to form a competitive electricity market. Restructuring of market has divided the main roles of a single monopoly entity to separate parties, which have such key participants as generation companies (GENCOs), transmission company (TRANSCO), distribution company (DISCO), retailers and end-users [1]. All the entities cooperate together to form an unbundled electricity market filling the need and requirement of every participant while maintaining a 'two-way' electricity trade: a satisfaction to all parties. As a result, a group of GENCOs will be able to sell their generated powers, which are transported via transmission and distribution system, to their buyers which are the end-users [2], [3]. There is another entity that plays a mastermind-like role: the Independent System Operator (ISO). Instead of owning a transmission system as TRANSCO, the ISO is responsible for coordinating, controlling and monitoring the system for secure, reliable and efficient market operation. Thus, it ensures a safe operation and management for the entire transmission grid of deregulated system. As a reward, the TRANSCO and ISO recover their operating cost by levying the market participants with transmission charges.
However, a problem did rise to prominence. In such a competitive electricity market, the way how to allocate the transmission charges became an incessantly debatable issue. In order to solve the problem, numerous researches have been conducted with an aim of establishing non-discriminatory scheme. It was reported that there are three embedded methods that consider actual network usage of a transaction, which are the postage stamp, contract path, and distance based MW-mile method [4]. Those techniques are based on transaction between point of injection and extraction of power in a transmission system. Many scholars and researchers did complain on the accuracy of such approach as they lack of physical considerations in power system: network topology, direction of power flow and actual usage based on contribution. Hence to counter the weakness, a rigorous method was invented: the electricity tracing. The keyword 'tracing' signifies a new scheme of charge allocation incorporating those physical considerations for more technical accuracy. In other words, the method traces the exact contribution of generators and loads in such commodities as line flows and losses at real situation of power system. On this basis, researchers are focusing on developing and proposing numerous tracing methods with the aim of offering non-discriminatory schemes to all market participants. Reliability of their works for practical applications has motivated the authors to conduct a survey on electricity tracing in losses charge allocation.

This paper presents a comprehensive review and analysis on various methods of losses charge allocation including the recent one that incorporates Artificial Intelligence (AI). The review starts by giving an overview on restructured power market, basic components of market operation and transmission charge concept. Later, a brief description on various categories of charge allocation methods is presented in chronological order, starting from transaction based method, followed by conventional electricity tracing and ended with computational intelligence approach. In the next section, a literature review on the performance of those methods are presented, analyzed and criticized. Finally, this paper ends with a solid conclusion that summarizes the whole aim of the authors.

\section{OVERVIEW ON RESTRUCTURED POWER MARKET}

The so-called deregulated electricity market, or restructured power market, means a power system with various 
market participants organized and handled by a single market operator, whose task is to operate the market while ensuring a secure and reliable system operation. Thus, the market is unbundled: every entity in such environment will have their specific tasks and operate independently under the authority of the market operator. Instead of being managed, operated and controlled by one utility as in vertically integrated system, which is a monopoly based, the restructured one promotes a competitive electricity market whereby every participant in the system will have their own right to compete and make choice for better services. Hence, this leads to customer's satisfaction and efficient system operation. There are three components in describing a restructured power market as follows [1]:

- Market structure - it describes the entities and types of market. The five market participants are generation companies (GENCOs), transmission companies (TRANSCOs), distribution companies (DISCOs), retail companies (RETAILCO) and consumers. These participants are headed and managed by a sole entity who acts independently as the market operator: the independent system operator (ISO).

- Market model - it explains how the energy trade (selling and buying) occurs. The first model, which is pool-based, constitutes a centralized model in which all participants, either sellers or buyers, submit their bids for energy price and quantity to the pool, a centralized marketplace. The second model, which is bilateral contract, promotes freedom of choice among sellers and buyers through a set of agreements in a specified contract between them.

- Market operation - it shows how the entities are interconnected in such competitive market. The key entities in the operation of competitive market are GENCOs and ISO. In contributing to market operation, they have specific aims set according to the needs of other participants and the system itself. While the ISO struggles to maintain an efficient market operation by ensuring a secure and reliable power system, the sole objective of GENCOs is a maximum profit.

The overall situation of the restructured power market is depicted in Fig. 1.

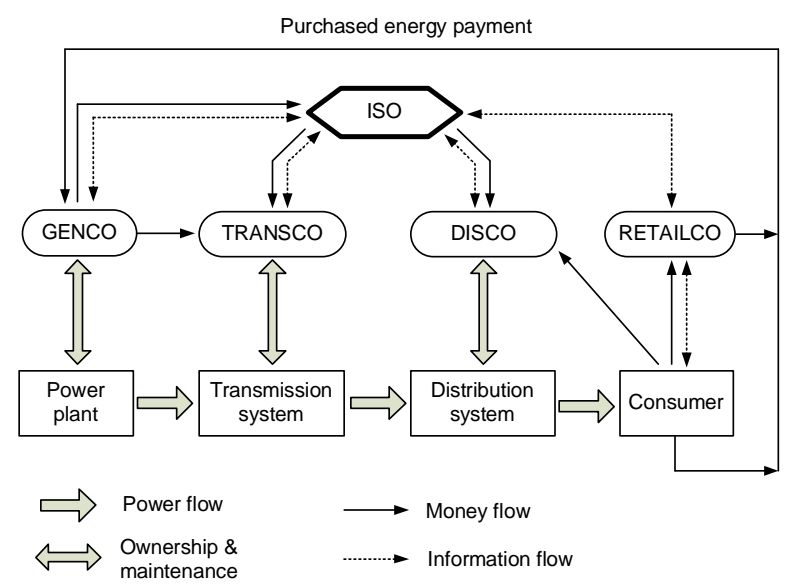

Figure 1: Restructured power market with its key participants

\section{VARIOUS LOSSES CHARGE ALLOCATION METHODS}

If GENCOs receive money from their buyers for the sold energy, then TRANSCO should receive payment from other market participants on the basis that they have used its transmission services and facilities for energy transaction. To make sense, those market participants (GENCOs, DISCOs, RETAILCOs and consumers) must be responsible to cover any transmission cost associated with their transactions. This is done by allocating the cost to the participants in the form of transmission charges [1]. In general, the charges can have usage charge, congestion charge and losses charge. Based on the reviews of the previous works, the losses charge can be allocated via the following methods:

- Transaction based allocation

- Conventional electricity tracing

- Computational intelligence based tracing

\subsection{Transaction based allocation}

Under the first category, there are three methods as follows: postage-stamp, contract path and MW-mile.

- Postage stamp allocation - This method allocates the losses charge to participants based solely on their magnitude of transacted power with an assumption that the entire grid is used during the transaction [1], [5]. Hence, it is a pro-rata approach. It also implies that the topology of network, direction of power flow, operational condition, transmission distance, injection and extraction point of power are ignored.

- Contract path method - The assumption that the entire grid is used during transaction is not technically reliable. Hence, to improve the weakness of postage stamp method, allocation of losses charge to network users is limited to artificial path specified by a contract: the contract path method [1], [6]. The artificial path is a group of transmission lines connected between a pair of power producer and buyer, whereby it is created according to contract agreed between TRANSCO and both participants. Thus, it is called as contract path. Through this contract, the transacted power between producer and buyer is assumed to flow along the contract path.

- $M W$-mile method - There is no power flow analysis required in the previous two methods as the losses charge is based on: (1) magnitude of transacted power and; (2) assumption on transmission path used by participants. The first ever method that determines actual transmission path used by the transacted power is MW-mile. The transmission path used by participants is technically identified without biased assumptions. For every transaction ' $t$ ' between a power producer and a buyer, the losses charge imposed on every line is calculated by the product of Megawatt loss, length of transmission line in miles and cost per unit loss and length agreed by both participants [7], [8]. 


\subsection{Conventional electricity tracing}

The second category will have the Topological Generation and Load Distribution Factor (TGLDF), state graph theory and superposition technique. The previous transaction based allocation techniques have some drawbacks in terms of technical accuracy. Hence, began a new phase of development on the methods of losses charge allocation: electricity tracing. The idea of tracing methods was firstly introduced by Bialek [9], [10] and Kirchens [11]. Most conventional tracing methods today originate from both pioneers, such as superposition based power tracing [12] and participation matrix tracing algorithm [13], [14].

a) Topological generation and load distribution factor This method was firstly introduced by Bialek in 1996 [9], [10]. The network is assumed to be topological in nature, connected and described by a set of nodes, directed links (transmission lines and transformers) and a set of sources and sinks (generators and loads). The so-called proportional sharing principle (PSP), which states that "an outflow leaving a node contains the same proportion of the inflows per total flows", becomes the basis of this method. The upstream looking algorithm is called Topological Generation Distribution Factor (TGDF), while the downstream algorithm is designated as Topological Load Distribution Factor (TLDF).

In using both algorithms, there are two concepts must be considered: gross demand and net generation. Gross demand means that the system losses are allocated to each load, while the net generation denotes the system losses are subtracted from each generator. Hence, the network is treated to be lossless during tracing process.

Contribution in gross line flow by all generators is:

$$
P_{i-j}^{\text {gross }}=\sum_{k=1}^{N_{G}} D_{i-j, k}^{\text {gross }} \cdot P_{G k}
$$

Contribution in gross load by all generators is:

$$
P_{D i}^{\text {gross }}=\sum_{k=1}^{N_{G}} D_{D i, k}^{\text {gross }} \cdot P_{G k}
$$

Where, the distribution factors and upstream matrix are determined as follows:

$$
\begin{gathered}
D_{i-j, k}^{\text {gross }}=\frac{\left|P_{i-j}\right|}{P_{i}}\left[\mathbf{A}_{\mathbf{u}}^{-\mathbf{1}}\right]_{i k} \\
D_{D i, k}^{\text {gross }}=\frac{P_{D i}}{P_{i}}\left[\mathbf{A}_{\mathbf{u}}^{-\mathbf{1}}\right]_{i k} \\
{\left[\mathbf{A}_{\mathbf{u}}\right]_{i j}=\left\{\begin{array}{cc}
1 & \text { for } i=j \\
-\left|P_{j-1}\right| / P_{j} & \text { for } j \in \alpha_{i}^{u} \\
0 & \text { otherwise }
\end{array}\right.}
\end{gathered}
$$

The allocated losses to individual generators and loads can be determined by firstly conducting TLDF for trac- ing net generation contributions. After that, the contributions in gross demand (in TGDF) and net generation (in TLDF) are used to calculate the allocated losses. This is performed through (6) and (7) for individual generators and loads respectively.

$$
\begin{aligned}
& P_{l}^{k}=\sum P_{D i, k}^{\text {gross }}-P_{G k}^{n e t} \\
& P_{l}^{k}=P_{D k}^{g r o s s}-\sum P_{G i, k}^{n e t}
\end{aligned}
$$

b) State graph theory:

The rival to Bialek's TGLDF is the one developed by Kirschen in [11]: the graph theory. If Bialek's method requires transformation of power system into lossless condition, the one from Kirschen necessitates for simplification of power system to state graph. The simplified system consists of commons and links, having their specific definitions. A common is a set of contiguous buses supplied by the same set of generators, while the link is a set of branches that interconnect commons. Generator domain, a set of buses supplied by a sole generator, shall be firstly identified prior to determining commons and links. As in Fig. 2, the dotted lines indicate three commons connected by links as follows: common $\mathrm{C} 1$ (bus 1 and 4), common $\mathrm{C} 2$ (bus 2, 3 and 5) and common $\mathrm{C} 3$ (bus 6); link L1 (line 1-2, 1-5 and 4-5) and link L2 (line 2-6, 3-6, and 5-6).

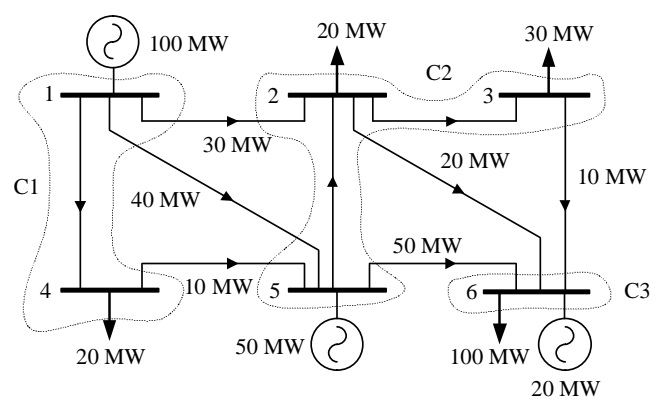

Figure 2: Power system marked with commons

The above power system can be represented in the form of state-graph as in Fig. 3.

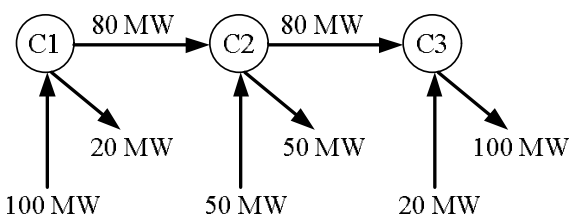

Figure 3: State graph for the 6-bus power system

The next stage is to trace the contribution of individual generators to line flows and loads recursively. This is done through the following equations:

$$
C_{o u t, k}^{i}=\frac{\sum_{j} P_{j k}^{i}}{P_{i n, k}}
$$




$$
\begin{gathered}
P_{j k}^{i}=C_{o u t, j}^{i} P_{j k} \\
P_{i n, k}=P_{G k}+\sum_{j} P_{j k}
\end{gathered}
$$

Equations (8), (9) and (10) represent the relative contribution, absolute contribution and total inflow respectively. The letter ' $j$ ' signifies a common that bring inflows to common ' $k$ '.

\section{c) Superposition technique:}

Bialek's tracing algorithm requires lossless power system and PSP assumption, while Kirschen's method requires complicated transformation of power system to state graph with recursive tracing process. Thus emerged a more sophisticated method developed by Teng [12], which can trace complex power without requiring modifications or assumptions as that of the previous tracing methods. This is called the superposition technique and it relies strictly on circuit theory. The tracing algorithm is based on four steps; (1) voltage tracing via basic Ohm's Law; (2) current tracing; (3) complex power tracing; and (4) losses tracing.

The equivalent current source and load impedance are determined as follows:

$$
\begin{gathered}
I_{G k}=\mathrm{conj}\left(\frac{P_{G k}+j Q_{G k}}{V_{G k}}\right) \\
Z_{D i}=\frac{\left|V_{D i}\right|^{2}}{P_{D i}-j Q_{D i}}
\end{gathered}
$$

The Z-bus matrix is formed by including the load impedance in (13). This is given below:

$$
\mathbf{Z}=\left[\begin{array}{ccccc}
Z_{11} & \cdots & Z_{1 k} & \cdots & Z_{1 N_{\text {bus }}} \\
\vdots & \ddots & \cdots & \cdots & \vdots \\
Z_{i 1} & \cdots & Z_{i k} & \cdots & Z_{i N_{\text {bus }}} \\
\vdots & \cdots & \cdots & \ddots & \vdots \\
Z_{N_{\text {bus }} 1} & \cdots & Z_{N_{\text {bus }} k} & \cdots & Z_{N_{\text {bus }} N_{\text {bus }}}
\end{array}\right]
$$

After that, contribution of generators in bus voltages is traced according to Ohm's Law. This is done as follows:

$$
V_{i}^{k}=Z_{i k} I_{G k}
$$

Later, generator contributions in line and load currents are determined through the following equations:

$$
\begin{gathered}
I_{i j}^{k}=y_{i j}\left(V_{i}^{k}-V_{j}^{k}\right)+j \frac{B}{2} V_{i}^{k} \\
I_{D i}^{k}=\frac{V_{i}^{k}}{Z_{D i}}
\end{gathered}
$$

After the contributed voltages and currents have been determined, the next step is to calculate the complex powers of line flow and load contributed by individual generators via the followings:

$$
\begin{aligned}
& S_{i j}^{k}=V_{i}^{k} \operatorname{conj}\left(I_{i j}^{k}\right) \\
& S_{D i}^{k}=V_{D i} \operatorname{conj}\left(I_{D i}^{k}\right)
\end{aligned}
$$

Finally, the losses allocated to individual generators are performed as below:

$$
S_{\text {loss }}^{k}=S_{i j}^{k}+S_{j i}^{k}
$$

Thus, the method promotes effectiveness as both real and reactive powers can be traced simultaneously.

\subsection{Computational intelligence based tracing}

The last one is based on the computational intelligence techniques, which can have prediction-based and optimization-based approach.

\section{a) Prediction based electricity tracing:}

The so-called Artificial Neural Network (ANN) is the heart of this method. Other function estimators may be employed, for instance the Support Vector Machine (SVM). The idea of formulating electricity tracing as a prediction or function estimation problem was pioneered by Shareef [15], Sulaiman [16] - [19] and Mustafa [20] [22]. In their proposed model, there are two types of data used in training process: input and target data. The former is obtained from daily load profiles (real and reactive power) and scheduled real power generation, while the latter is acquired from the tracing results of conventional tracing methods. This implies that prior to running the developed predictive model, it is compulsory to provide the target data by executing electricity tracing through such conventional methods as TGLDF or superposition. This is illustrated in Fig. 4.

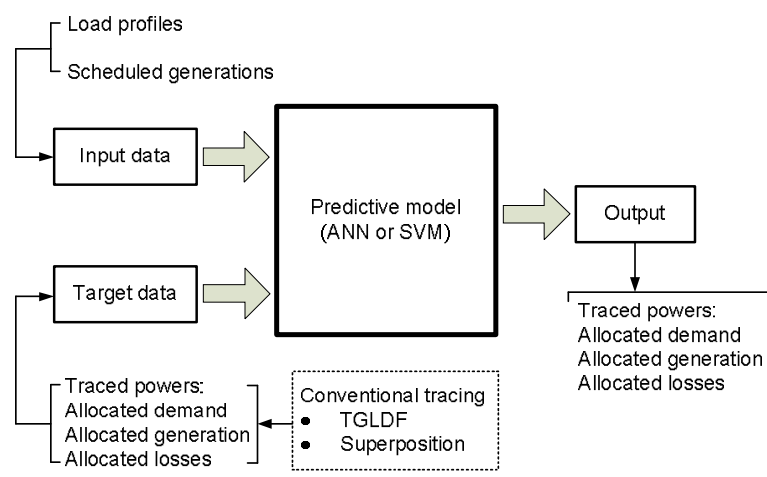

Figure 4: Prediction based tracing model

Basically, there is no mathematical derivation required by the user of this approach. The only things to be concerned are the conventional tracing method to be applied as a 'teacher', partition of data for training-testing and other internal parameters related to the predictive model such as number of neurons and hidden layers for ANN, or kernel and regularization parameters for SVM. This 
promotes simplicity during problem formulation. The dependence on conventional tracing methods limits the uniqueness of its output, however.

Thus, by feeding in the input and target data, the predictive model will be trained and tested. Afterwards, the trained model is verified by supplying new input data to perform the prediction (or estimation). Eventually, the allocated powers and losses to participants (generators and loads) are produced as its output. This is summarized in the flowchart as in Fig. 5.

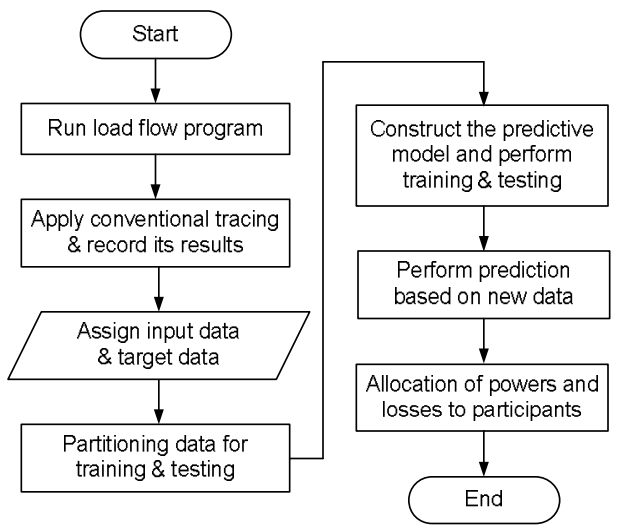

Figure 5: Algorithm for prediction based tracing

\section{b) Optimization based tracing:}

The rarest and unthinkable approach for electricity tracing is the one that employs optimization. In [23], for the first time Abhyankar has proven the ability of optimization for tracing application. Too many constraints, equations and complex mathematical considerations constitute its drawbacks for real applications. This is exacerbated by an obscure process involved in the method as there is no algorithm or flowchart was shown.

Later, Hamid further clarified the methodology through a simple problem formulation using such metaheuristic optimization techniques as the Evolutionary Programming (EP) and the Ant Colony Optimization (ACO) [24], [25]. In general, the proposed problem formulation was inspired by that of Abhyankar [23] with some modifications. There are three components to be specified accordingly prior to using an optimization technique: decision variables, constraints and objective function. Decision variables consist of contribution fractions (generators and loads) in line flow and losses which are placed in a large matrix to represent an individual of population in the optimization algorithm. The constraints are based on that of Abhyankar: flow constraint, source and sink constraints and fraction limit constraints. To reflect a more technical accuracy of the proposed method, Hamid derived an objective function based on generation-demand balance concept. The proposed model is shown in Fig. 6.

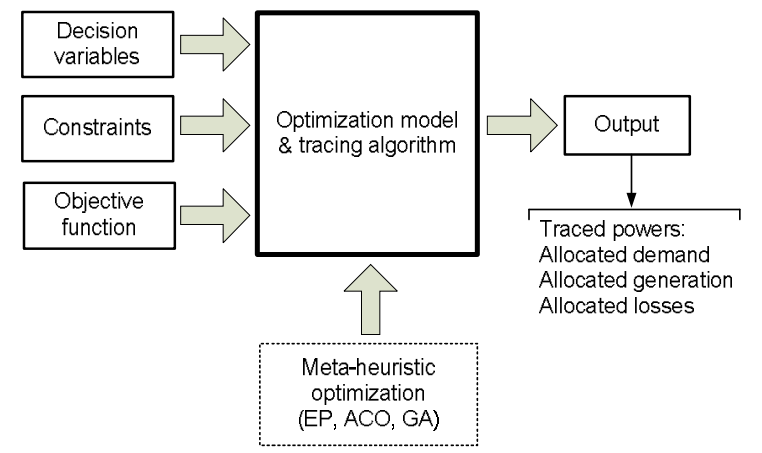

Figure 6: Optimization based tracing model

The following problem formulation is presented in the context of generation tracing, but it can also be modified for the purpose of load tracing.

Objective function:

$$
\min \left\{f\left(\beta_{D i}^{k}, \beta_{\text {loss }, l}^{k}\right)=1-\sum_{i=1}^{N_{D}} \beta_{D i}^{k}-\sum_{l=1}^{N_{L}} \beta_{\text {loss }, l}^{k}\right\}
$$

Decision variables:

$$
\mathbf{S}_{\mathbf{G T}}=\left[\beta_{1}, \beta_{2}, \ldots, \beta_{n}, \ldots, \beta_{N}\right]
$$

Subject to constraints in [23]:

$$
\begin{gathered}
P_{f l}=\sum_{k=1}^{N_{G}} \beta_{f l}^{k} P_{G k} \\
P_{D i}=\sum_{k=1}^{N_{G}} \beta_{D i}^{k} P_{G k} \\
0 \leq \beta \leq 1, \quad \forall \beta \text { in } \mathbf{S}_{\mathrm{GT}}
\end{gathered}
$$

Finally, the allocated losses to individual generators and loads for $l$-th line are calculated via (25) and (26) respectively:

$$
\begin{aligned}
& P_{l o s s, l}^{k}=\beta_{s l}^{k} P_{G k}\left(1-\frac{P_{r l}}{P_{s l}}\right) \\
& P_{l o s s, l}^{k}=\beta_{r l}^{k} P_{D k}\left(\frac{P_{s l}}{P_{r l}}-1\right)
\end{aligned}
$$

The proposed algorithm using meta-heuristic optimization technique is illustrated in Fig. 7. In the diagram, the algorithm performs optimization with the aim of minimizing fitness in (20) towards zero. 


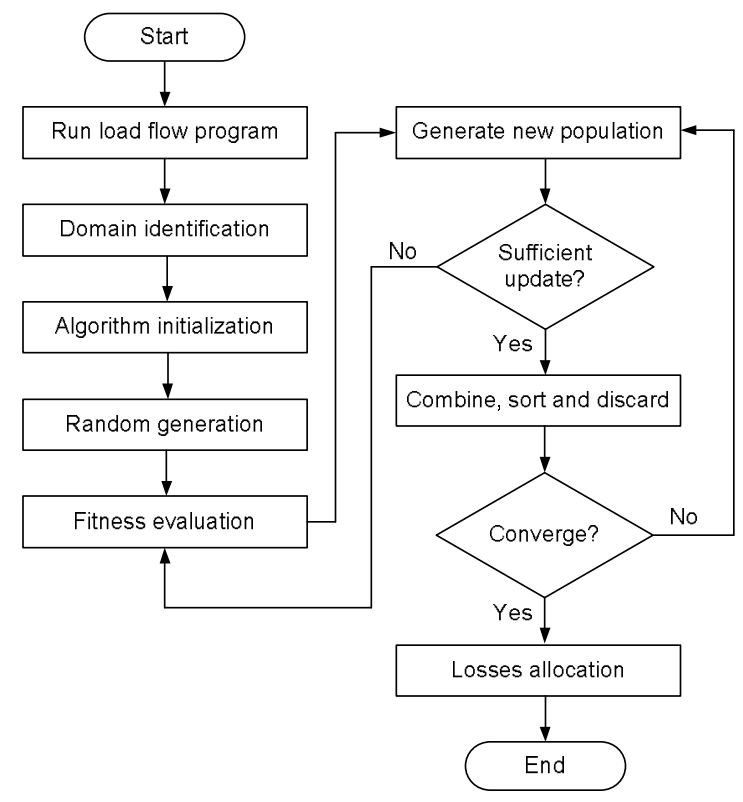

Figure 7: Optimization based tracing algorithm

\section{REVIEW AND FINDINGS}

This section presents related reviews on losses charge issues in deregulated power market. It begins with traditional methods of losses charge allocation and their limitations regarding how accurate and reliable the scheme they offered. After that, reviews on application of electricity tracing are presented and comparison in terms of their performance is summarized.

\subsection{Losses charge allocation through traditional me- thods}

Among the traditional methods, the most commonly implemented was the megawatt-mile (MW-mile). Usually, a DC load flow analysis is required for the method to simulate a transaction between two nodes, but an AC load flow can also be the alternative. As conducted in [26] and [27], the technique included the length of transmission line and direction of power flow in the proposed losses charge equations. With regard to power flow direction, three approaches of MW-mile method are the absolute MW-mile, dominant MW-mile, and reverse MW-mile [28]. In the absolute approach, any reversed power flow was treated equivalently to that of normal power flow. The dominant approach considered only the normal power flow with zero reversed flow, while the reverse MW-mile took into consideration the sign of each flow. This means that normal flow will have positive sign, while reverse flow shall take the negative one. All the approaches affected the charge allocation trend as they offered different consideration on power flow direction.

Article [29] applied the MW-mile for transmission charge allocation to real and reactive loads. To obtain reliable usage, the research implemented tracing algorithm for determining load contribution in line flow. The experiment results revealed that it was effective to perform tracing of power prior to allocating the charge. This is due to the fact that the technique was applicable for both real and reactive power allocation. Another work that also incorporated a tracing technique with the MWmile was performed in [30] using justified distribution factor. To provide reliable transmission cost allocation, the research took account of the economic benefits by determining users' negative flow or counter flow. After comparison, it was validated that regardless of transaction arrangement and locations of traders, the technique was better than traditional MW-mile approaches in terms of revenue reconciliation. Later, because of the conventional MW-mile did not consider reactive power based usage, article [31] proposed a novel approach, the MVAmile, for taking into account both real and reactive power in the pricing scheme. Through this method, it eliminated the drawbacks of the traditional MW-mile as it did offer a more robust scheme: simultaneous real and reactive charge allocation.

Besides the MW-mile, the frequently used method in losses charge problem is the so-called postage stamp, or pro-rata. According to [32], despite of simplicity offered by postage stamp in the losses charge allocation, the technique was less reliable as the network topology was ignored. In calculating the allocated charge, only the seller's generated power and consumer's extracted power were taken into consideration regardless of their actual usage, contribution, and direction of power flow. In the research performed by [33], three allocation techniques were compared in terms of reliability: postage stamp, incremental transmission loss (ITL) and proportional sharing. It was reported that proportional sharing was the best technique as it was able to trace generator and load contribution with positive loss values. ITL has disadvantages in terms of volatile results, negative allocated losses, and required normalization procedure. In addition, the research stated that although the postage stamp was the most popular technique employed by many utilities, it failed to establish a transparent scheme. Later, article [34] compared the performance of three methods namely the postage stamp, proportional sharing, and novel pricing method. The research verified the conclusion drawn by [33] with proportional sharing and novel pricing being the most effective methods and more reliable than postage stamp.

Next for the first time, article [35] and [36] proposed an alternative concept for transmission loss allocation via the incremental transmission loss (ITL). To implement it correctly, the research stated that it is necessary to specify the load distribution and loss supply strategies. Based on the research, it was found that ITL was a type of sensitivity analysis, that is, the allocation was based on the change of transmission losses with respect to power injection at a particular bus. After experimentation, it was reported that ITL was suitable for non-discriminatory purpose. The compatibility of ITL to be used in losses charge problem was also verified by article [37]. Later, a comprehensive research was performed by [38] including four types of loss allocation methods; postage stamp, ITL, proportional sharing and Z-bus matrix. To perform a more reliable experiment, load flow was simulated under base case and addition of load at a certain bus. This was important to observe the allocation trend if the system was subjected to any types of disturbances. It was 
found that the postage stamp did the allocation independent of network topology, which could be a drawback, while the ITL and Z-bus matrix resulted in both positive and negative losses charge which could lead to discriminatory fashion. This is because other buses receiving positive allocated losses must pay some kind of incentives to the remaining buses with negative allocated losses.

\subsection{Losses charge allocation through conventional electricity tracing}

From article [39], it can be defined that tracing the flow of electricity (sometimes known as power tracing) deals with the determination of contribution factors of generators in line flows, losses, and load powers or conversely, of extraction factors of loads in line flows, losses, and generator powers. To be clear, it traces the percentage of generator and load contribution in line flows and losses in order that the traced information can be used for fair usage charge allocation and congestion analysis. From that, the market participants are disclosed about how much they will be charged for the associated usage capacity. This transparent scheme has made the power tracing as an alternative besides traditional methods. Due to this fact, it has triggered the development of various power tracing approaches for more efficient scheme of transmission pricing.

In 1996, for the first time, the proportional sharing principle (PSP) was introduced by Bialek [9], [10] for explaining the assumption used in the problem formulation. Based on topological approach, the proposed technique was known as the Topological Generator and Load Distribution Factor (TGDLF) which consists of two algorithms; upstream and downstream looking algorithm. In TGLDF, treating the power system to be lossless is a must before implementing the algorithm. This can be achieved by adding the contributed losses to each load to be gross demand (for upstream algorithm), or subtracting the contributed losses from generator's power to be net generation (for downstream algorithm). Due to such modification, it was revealed that the tracing results produced by TGLDF were not in actual condition of the system. Instead, it was based on lossless line flow. In addition, relying on matrix inversion during tracing process is a risk as there is always possibility for the matrix to be singular. This happens especially at contingency or any uncertainties in the power system.

A year later, after PSP was introduced, graph theory was firstly proposed by Kirschen in [11]. In the method, the concept of domain, common, link, and state graph was introduced and illustrated with a simple power system. Contrary to TGLDF that required a lossless system, Kirschen's power tracing demanded for network simplification: from a complex power system to a simple stage graph. Thus, in the research, the simplification to a state graph comprising of only nodes (commons) and lines connecting those nodes (links) were presented properly. Although the technique offered a tracing algorithm under actual system condition, dependency on PSP as in TGLDF was still required. Theoretically, the tracing results were still based on assumption. In addition, as reported by [22] there would be a problem from common and link concept as the share of all generators located in each common were assumed to be the same regardless of their generated power. Further application of graph theory was proposed by [40] and [41]. In [40], the graph theory was used for detection of circulating power and subsequently, it was eliminated via optimal power flow (OPF). The technique was reported to be suitable for active and reactive power tracing with the presence of circulating power. However, all the previous methods were only applicable for separate real and reactive power tracing. The algorithm for real power tracing cannot be used straightforwardly in reactive power tracing problem as the effect of shunt capacitance and inductance of transmission lines affect the power flow direction.

In 2005, about a decade after TGLDF and graph theory were introduced, a circuit theory based power tracing was proposed by Teng [12] for simultaneous real and reactive power tracing. Without requiring any assumptions and matrix inversions, the method relied on basic Ohm's Law: the contributed voltage by a generator was traced via multiplication between bus impedance matrix (Z-bus matrix) and generator's current vector. From that, the complex powers contributed by individual generators were traced by multiplying the contributed voltages and currents through $S=V I^{*}$. To implement the technique, all generators were modeled as an equivalent current source, while the loads were converted to equivalent shunt impedances. Although the method was able to trace complex powers contributed by generators rather than performing separate real and reactive power tracing as in other methods, the negative sharing was an unavoidable problem. This will cause confusion in transmission service pricing due to negative allocated charge. Later, complex power tracing was also offered by [42] using nominal-T model of transmission line. Although it was able to give traced complex powers as in [12], dependency on PSP and graph theory was still required. Complex losses allocation was proposed by [43] with the application of Current Adjustment Factor (CAF) for considering the non-linearity behavior of the system. The research validated the capability of circuit theory for accurate tracing results by increasing participation of generators in the tracing scheme.

Subsequently, allocation of real power losses to generators and loads was proposed by [44]. Instead of using the original Z-bus matrix as in [12], the research implemented a tracing algorithm via modified Z-bus matrix which expressed the real power losses in terms of generator and load current. From that, the losses allocation to generators and loads can be determined separately with more accurate results. Later, article [45] proposed an algorithm for tracing active power flow by means of extended incident matrix. By modeling analytically the transfers of power between generators and loads, the traced power flows were determined without requiring PSP. It was also stated that the proposed method was applicable for any power system either with or without circulating power. Afterwards, a unique tracing algorithm was proposed by Abdelkader [13], [14] without difficult concept, assumption, and problem formulation. Elimination of negative elements in participation matrix was used during the tracing process. However, after testing on large test system, the technique was only viable 
for a system which has only one generator or load at a particular bus. If both of them are present at a bus, the tracing results will be unreliable.

\subsection{Losses charge allocation through computational intelligence based tracing}

Application of Artificial Intelligence (AI) for solving losses allocation problem was firstly exploited by [46] using the Artificial Neural Network (ANN): a prediction based tracing algorithm. The idea was further implemented by Choudhury in [47]: the ANN was used for transmission losses allocation using two network structures, the Levenberg-Marquardt back propagation (LMBP) and the Bayesian regularization back propagation (BRBP). In providing better ANN performance in terms of computation time, a filtering technique was proposed to filter the data required in the training task. This is to improve the training data volume requirement. It was validated that both trained network structures resulted in promising outputs within tolerable computation time.

The performance of prediction based tracing was further verified in the research conducted by Mustafa [20]. In the proposed technique, the target vector for ANN's training process was based on modified nodal equation technique in which the decomposed load current from a partitioned Y-bus matrix and load voltage from power flow results were used for tracing the generator contribution in that load. It was revealed that ANN was able to give promising results with better accuracy and computation time as compared to the original nodal equation technique. In analogous to the research using ANN, for the first time, Mustafa in [21] implemented another prediction technique for solving the same problem: the Support Vector Machine (SVM). In contrast to [20], PSP was used for constructing the target vector. In providing optimal performance, the parameters of SVM (regularization parameter and kernel radial basis function) were tuned using the Genetic Algorithm (GA), and after validation, it was justified that the proposed GA-SVM gave better accuracy and speed than ANN. After the capability of SVM was proven, Sulaiman in [19] formulated a new prediction algorithm via SVM. Implementation of superposition method for constructing the target vector together with the Artificial Bee Colony (ABC) algorithm for replacing GA in [21] (hence, ABC-SVM) has proven the capability of AI as an alternative for electricity tracing. In fact, the only differences between the works con- ducted in [19] - [21] were the techniques for constructing the target vector and the prediction tools applied. Modified nodal equation, PSP, and superposition method were used for constructing the target vector, while the ANN and SVM being their prediction tools.

The most controversial research was conducted by Abhyankar [23] after it criticized Bialek's PSP. In the research, it was said that the dependency on PSP has made the participation factors of generators and loads to be 'frozen'. Thus, to make it changeable based on desired objective, an optimization based real power tracing was firstly proposed in 2006. In the problem formulation, the only things to be known were the control variables, constraints, and fitness to be optimized. There was no assumption and concept as required by other conventional tracing algorithms. However, the proposed technique was burdensome in terms of computation time due to large number of control variables and constraints to be considered, especially when dealing with a large scale power system. Later, due to Abhyankar's idea, an AIbased-optimization technique for power tracing using Genetic Algorithm (GA) was proposed by [16]. Contrary to [23], the technique formulated the problem with simple equations and constraints; making it more preferable to be implemented. However, the lack of considering other possible constraints has made the tracing results less accurate. In 2012, about six years after Abhyankar's idea, Hamid [24], [25] proposed a new tracing algorithm through optimization. To try a different approach with new problem formulation, the research proposed AIbased-optimization for both generation tracing and load tracing. The fractions of generator contribution and load extraction were treated as the decision variables, together with some constraints proposed by [23] and a new objective function derived based on generation-demand balance equation. In selecting the optimization engine, the research applied Evolutionary Programming (EP) for generation tracing. After successful implementation, a new hybrid algorithm was proposed to reduce the computational burden experienced in the previous work: the Blended Crossover Continuous Ant Colony Optimization (BX-CACO). It was justified that the proposed technique gave reliable tracing results as other conventional tracing algorithms did. The technique, in addition, was free from assumption, matrix singularity and can perform the tracing process under real system condition. Thus, the lossless condition of power system as required by Bialek's TGLDF and simplification to Kirschen's state graph were successfully avoided. The computational burden,

Table 1: summary of various methods for losses charge allocation

\begin{tabular}{|c|c|c|c|c|c|}
\hline Category & Method & $\begin{array}{l}\text { Payment } \\
\text { method }\end{array}$ & Main principle & Strength & Weakness \\
\hline \multirow[t]{4}{*}{$\begin{array}{l}\text { Transaction } \\
\text { based }\end{array}$} & $\begin{array}{l}\text { Postage } \\
\text { stamp }\end{array}$ & $\begin{array}{l}\text { Transacted } \\
\text { power }\end{array}$ & $\begin{array}{l}\text { Pro rata based alloca- } \\
\text { tion }\end{array}$ & $\begin{array}{l}\text { Easy and simple for implementa- } \\
\text { tion }\end{array}$ & $\begin{array}{l}\text { Physical power system is not } \\
\text { considered }\end{array}$ \\
\hline & Contract path & $\begin{array}{l}\text { Transacted } \\
\text { power }\end{array}$ & $\begin{array}{l}\text { Allocation based on the } \\
\text { chosen lines }\end{array}$ & $\begin{array}{l}\text { Easy and simple for implementa- } \\
\text { tion }\end{array}$ & $\begin{array}{l}\text { Assumption for the lines used } \\
\text { in the contract }\end{array}$ \\
\hline & MW-mile & $\begin{array}{l}\text { Transacted } \\
\text { power }\end{array}$ & $\begin{array}{l}\text { Distance based alloca- } \\
\text { tion }\end{array}$ & $\begin{array}{l}\text { Length of transmission lines is } \\
\text { considered }\end{array}$ & $\begin{array}{l}\text { Cost per length has to be } \\
\text { agreed between seller \& buyer }\end{array}$ \\
\hline & ITL & $\begin{array}{l}\text { Transacted } \\
\text { power }\end{array}$ & Sensitivity analysis & $\begin{array}{l}\text { Contribution in losses is consi- } \\
\text { dered through sensitivity index }\end{array}$ & $\begin{array}{l}\text { Negative participation among } \\
\text { generators \& loads }\end{array}$ \\
\hline \multirow[t]{3}{*}{$\begin{array}{l}\text { Conventional } \\
\text { tracing }\end{array}$} & $\begin{array}{l}\text { Bialek's } \\
\text { TGLDF }\end{array}$ & $\begin{array}{l}\text { Contributed } \\
\text { power }\end{array}$ & Proportional sharing & $\begin{array}{l}\text { No negative participation among } \\
\text { generators \& loads }\end{array}$ & $\begin{array}{l}\text { Require matrix inversion \& } \\
\text { lossless system }\end{array}$ \\
\hline & $\begin{array}{l}\text { Kirschen's } \\
\text { graph theory }\end{array}$ & $\begin{array}{l}\text { Contributed } \\
\text { power }\end{array}$ & $\begin{array}{l}\text { Commons, links and } \\
\text { state graph }\end{array}$ & $\begin{array}{l}\text { Power system is simplified to } \\
\text { facilitate the tracing process }\end{array}$ & $\begin{array}{l}\text { Same contribution for all gene- } \\
\text { rators of each common }\end{array}$ \\
\hline & $\begin{array}{l}\text { Teng's super- } \\
\text { position }\end{array}$ & $\begin{array}{l}\text { Contributed } \\
\text { power }\end{array}$ & Circuit theory & $\begin{array}{l}\text { Simultaneous real \& reactive } \\
\text { power tracing }\end{array}$ & $\begin{array}{l}\text { Negative participation among } \\
\text { generators \& loads }\end{array}$ \\
\hline \multirow[t]{2}{*}{$\begin{array}{l}\text { Computational } \\
\text { intelligence }\end{array}$} & Prediction & $\begin{array}{l}\text { Contributed } \\
\text { power }\end{array}$ & Predictive model & $\begin{array}{l}\text { Applicable at all possible system } \\
\text { conditions }\end{array}$ & $\begin{array}{l}\text { Require conventional methods } \\
\text { for training vector }\end{array}$ \\
\hline & Optimization & $\begin{array}{l}\text { Contributed } \\
\text { nnwar }\end{array}$ & Optimization model & $\begin{array}{l}\text { Applicable at all possible system } \\
\text { mnditions }\end{array}$ & $\begin{array}{l}\text { Computational burden for } \\
\text { larmar crretem }\end{array}$ \\
\hline
\end{tabular}


however, remained the main issue of this approach if the tracing is intended for a large scale power system.

\subsection{Summary of reviews}

After reviewing the previous methods of losses charge allocation, their strength and weakness are summarized in Table 1. From the table, the transaction based methods impose the payment on market participants based on transacted power, which is the purchased power agreed between seller and buyer. In contrast to this approach, the other methods rely on exact usage in powers and losses, which is the contributed power by individual participants considering physical network topology, power flow direction and other technical aspects of the system. Hence, the electricity tracing approaches, both the conventional and computational intelligence, necessitate for load flow analysis to perform technically accurate allocation of losses charges.

Different methods require different problem formulation and principles. Most of the transaction based methods lack of actual consideration as they ignore real situation of the system: the load flow analysis concerns only the flow of powers between two parties (seller and buyer). In fact, not all powers come directly from a single generator and absorbed fully by a single load. Hence, there is a need to determine how much percentage of participation by individual users of the system. The only approach that can achieve such requirement is undeniably the electricity tracing.

Table 1 proves that all methods have their own strength and weakness, no one is perfect. As mentioned before, transaction based methods did offer simplicity and ease of implementation in practical problems. This is not the case, however. Accuracy of results is provided by conventional tracing methods, but still they require certain principles to facilitate the process of tracing. In addition, some of them are unable to yield any results if the power system is at contingency. Versatility of computational intelligence approaches has elevated their prominence among other methods. The tracing results are available at any possible conditions of the system. Nevertheless, depending on conventional tracing for a training vector in predictive models limits their uniqueness in the results, while the computational burden experienced by optimization models restricts their applications in practical systems.

\section{CONCLUSION}

In brief, a survey on the key components of deregulated power market and various methods of losses charge allocation was successfully conducted. This survey aims to provide an introductory review to all researchers and new readers who are interested in electricity deregulation and restructured power market. They can treat the findings presented in this paper as a reference for their future research, and a justification for the choice they will make regarding the suitable methods to be used. The highlighted reviews presented here are not intended to shine certain methods while discriminating the others, but as comparative studies to promote a proper choice based on academic findings. Therefore, it is aspired that this sur- vey will increase participation among academicians in the research concerning restructured power market.

\section{ACKNOWLEDGEMENT}

The authors would like to acknowledge the Research Management Centre (RMC), Office of Deputy Vice Chancellor (DVC), Universiti Teknologi MARA (UiTM) Shah Alam, Selangor, Malaysia for the financial support of this research. This research is supported by RMC under the Research Entity Initiative (REI) Grant Scheme with project code: 600-IRMI/REI 5/3 (011/2018).

\section{REFERENCES}

[1] H. Yamin. M. Shahidehpour, Z. Li, Market Operations in Electric Power Systems: Forecasting, Scheduling, and Risk Management. New York: John Wiley and Sons, Inc., 2002.

https://doi.org/10.1002/047122412X

[2] N.A Adnan, M.H Mansor, N. Roslan, I. Musirin, "Multi-objective evolutionary programming for solving economic dispatch problem", International Journal of Advanced Trends in Computer Science and Engineering, Vol. 8, Issue 1.6, Special Issue, 2019, No. 44, pp. 296-302.

https://doi.org/10.30534/ijatcse/2019/4481.62019

[3] N.M.M. Farid, I. Musirin, N.H.S. Hannon, M. Amroune, "Evolutionary symbiotic organisms search technique in power scheduling for loss control in power transmission system", International Journal of Advanced Trends in Computer Science and Engineering, Vol. 8, Issue 1.3 S1, 2019, No. 74, pp. 431-437.

https://doi.org/10.30534/ijatcse/2019/7481.32019

[4] G. A. Orfanos, G. T. Tziasiou, P. S. Georgilakis, and N. D. Hatziargyriou, "Evaluation of transmission pricing methodologies for pool based electricity markets," in the IEEE Trondheim PowerTech, 2011, pp. 1 - 8.

[5] N. H. Radzi, R. C. Bansal, Z. Y. Dong, "New Australian NEM transmission use of system charging methodologies for integrating renewable generation to existing grid", Renewable Energy, Vol. 76, pp. $72-81,2015$. https://doi.org/10.1016/j.renene.2014.10.072

[6] Po-Han Chen, Ing-Sheng Tsay, "Transmission network price setting model for the promotion of liberalized market for the power industry in Taiwan", Energy Policy, Vol. 104, pp. 100 - 111, 2017.

[7] Tiago Soaresa, Fabio Pereirab, Hugo Moraisb, Zita Vale, "Cost allocation model for distribution networks considering high penetration of distributed energy resources", Electric Power Systems Research, Vol. 124, pp. 120 - 132, 2015.

[8] N.H. Radzi, R.C. Bansal, Z.Y. Dongc, M.Y. Hassand, K.P. Wong, "An efficient distribution factors enhanced transmission pricing method for Australian NEM transmission charging scheme", Renewable Energy, Vol. 53, pp. 319 - 328, 2013. https://doi.org/10.1016/j.epsr.2015.03.008 
[9] J. Bialek, "Tracing the flow of electricity," IEE Proceedings on Generation, Transmission and Distribution, vol. 143, no. 4, pp. 313 - 320, 1996.

[10] J. Bialek, "Topological generation and load distribution factors for supplement charge allocation in transmission open access," IEEE Transactions on Power Systems, vol. 12, no. 3, pp. 1185 - 1193, 1997. https://doi.org/10.1109/59.630460

[11] D. Kirschen, R. Allan, and G. Strbac, "Contributions of individual generators to loads and flows," IEEE Transactions on Power Systems, vol. 12, no. 1, pp. 52 - 60, 1997.

[12] J. H. Teng, "Power flow and loss allocation for deregulated transmission systems," International Journal of Electrical Power and Energy Systems, vol. 27, no. 4, pp. 327 - 333, 2005.

[13] S. Abdelkader, "A method for determining generators' shares in loads, line flows and losses," Journal of the Franklin Institute, vol. 344, no. 8, pp. 1063 1074, 2007. https://doi.org/10.1016/j.jfranklin.2007.05.004

[14] S. Abdelkader, "Determining generators' contribution to loads and line flows and losses considering loop flows," International Journal of Electrical Power and Energy Systems, vol. 30, no. 6 - 7, pp. 368 - 375, 2008.

[15] H. Shareef and M. W. Mustafa, "A Hybrid Power Transfer Allocation Approach for Deregulated Power Systems," in the IEEE International Power and Energy Conference (PECon), 2006, pp. 215 219.

[16] M. H. Sulaiman, M. W. Mustafa, and O. Aliman, "Transmission loss and load flow allocations via genetic algorithm technique," in the IEEE Region 10 Conference (TENCON), 2009, pp. 1 - 5.

[17] M. H. Sulaiman, M. W. Mustafa, O. Aliman, I. Daut, S. H. Amrin, and M. S. A. Hassan, "Tracing reactive power flow and loss in electric power systems," International Energy Journal, vol. 10, no. 1, pp. 45 - 54, 2009.

[18] M. H. Sulaiman, M. W. Mustafa, and O. Aliman, "Power flow and loss tracing in deregulated transmission system using proportional tree method," International Review of Electrical Engineering, vol. 3, no. 4, pp. 691 - 698, 2008.

[19] M. H. Sulaiman, M. W. Mustafa, H. Shareef, and S. N. Abd. Khalid, "An application of artificial bee colony algorithm with least squares support vector machine for real and reactive power tracing in deregulated power system," International Journal of Electrical Power and Energy Systems, vol. 37, no. 1, pp. 67 - 77, 2012.

[20] M. W. Mustafa, S. N. Khalid, H. Shareef, and A. Khairuddin, "Reactive power transfer allocation method with the application of artificial neural network," IET on Generation, Transmission and Distribution, vol. 2, no. 3, pp. 402 - 413, 2008. https://doi.org/10.1049/iet-gtd:20070354

[21] M. W. Mustafa, M. H. Sulaiman, H. Shareef, and S. N. A. Khalid, "Reactive power tracing in poolbased power system utilising the hybrid genetic algorithm and least squares support vector machine,"
IET on Generation, Transmission and Distribution, vol. 6, no. 2, pp. 133 - 141, 2012.

[22] M. W. Mustafa, H. Shareef, and M. R. Ahmad, "An improved usage allocation method for deregulated transmission systems," in the 7th International Power Engineering Conference (IPEC), 2005.

[23] A. R. Abhyankar, S. A. Soman, and S. A. Khaparde, "Optimization approach to real power tracing: an application to transmission fixed cost allocation," IEEE Transactions on Power Systems, vol. 21, no. 3, pp. 1350 - 1361, 2006. https://doi.org/10.1109/TPWRS.2006.879278

[24] Z. Hamid, I. Musirin, M. M. Othman, and M. N. A. Rahim, "New formulation technique for generation tracing via evolutionary programming," International Review of Electrical Engineering, vol. 6, no. 4, pp. 1946 - 1959, 2011.

[25] Z. Hamid, I. Musirin, M. N. A. Rahim, and N. A. M. Kamari, "Optimization assisted load tracing via hybrid ant colony algorithm for deregulated power system," WSEAS Transactions on Power Systems, vol. 7, no. 3, pp. 145 - 158. 2012.

[26] B. Kharbas, M. Fozdar, and H. Tiwari, "Transmission tariff allocation using combined MW-Mile and Postage stamp methods," in the IEEE PES Innovative Smart Grid Technologies - India (ISGT India), 2011, pp. 6 - 11. 248

[27] M. Z. Meah, A. Mohamed, and S. Serwan, "Comparative analysis of using MW-Mile methods in transmission cost allocation for the Malaysia power system," in the Proceedings of National Power Engineering Conference (PECon), 2003, pp. 379 - 382.

[28] S. C. Raja, R. Elakkia, and P. Venkatesh, "A new transmission pricing methodology for Indian restructured market using PSS/E software," in the International Conference on Recent Advancements in Electrical, Electronics and Control Engineering (ICONRAEeCE), 2011, pp. 488 - 492.

[29] J. Bialek, "Allocation of transmission supplementary charge to real and reactive loads," IEEE Transactions on Power Systems, vol. 13, no. 3, pp. 749 754, 1998. https://doi.org/10.1109/59.708576

[30] K. L. Lo, M. Y. Hassan, and S. Jovanovic, "Assessment of MW-mile method for pricing transmission services: a negative flow-sharing approach," IET Generation, Transmission and Distribution, vol. 1, no. 6, pp. 904 - 911, 2007.

[31] N. Kumar, Y. R. V. Reddy, D. Das, and N. P. Padhy, "Allocation of transmission charge by using MVA-Mile approaches for restructured Indian power utility," in the IEEE Power and Energy Society General Meeting, 2011, pp. 1 - 6.

[32] Q. Ding and A. Abur, "A unified transmission loss allocation method," International Journal of Electrical Power and Energy Systems, vol. 29, no. 5, pp. 380 - 386, 2007.

[33] F. Ansyari, C. S. Ozveren, and D. King, "Comparison of loss allocation methods in a regulated system (A case study at Java-Bali 500KV Grid System in Indonesia)," in the 43rd International Conference on Universities Power Engineering (UPEC), 2008. pp. 1 - 5 . 
[34] A. N. Ramani and K. A. Baharin, "Transmission losses allocation in deregulation electricity market," in the IEEE International Conference on Power and Energy (PECon), 2010, pp. 841 - 845.

[35] F. D. Galiana and M. Phelan, "Allocation of transmission losses to bilateral contracts in a competitive environment," IEEE Transactions on Power Systems, vol. 15, no. 1, pp. 143 - 150, 2000.

[36] F. D. Galiana, A. J. Conejo, and I. Kockar, "Incremental transmission loss allocation under pool dispatch," IEEE Transactions on Power Systems, vol. 17 , no. 1 , pp. 26 - 33, 2002. https://doi.org/10.1109/59.982189

[37] R. S. Ferreira, M. M. Carvalho, L. A. Barroso, B. Bezerra, L. M. Thome, and M. V. Pereira, "Impacts of causal transmission losses allocation on generation pricing for long-term contracts in Brazil," in the Sixth IEEE/PES Transmission and Distribution: Latin America Conference and Exposition (T\&DLA), 2012, pp. 1 - 10.

[38] D. A. Lima and A. Padilha-Feltrin, "Allocation of the costs of transmission losses," Electric Power Systems Research, vol. 72, no. 1, pp. 13 - 20, 2004.

[39] N. B. Dev Choudhury, D. Prajapati, and R. K. Kakoti, "Identification of transmission loss in trading of power using tracing of power," in the $9^{\text {th }}$ International Conference on Electrical Engineering/Electronics, Computer, Telecommunications and Information Technology (ECTI-CON), 2012, pp. 1-4.

[40] P. Wei, Y. Ni, and F. F. Wu, "Load flow tracing in power systems with circulating power," International Journal of Electrical Power and Energy Systems, vol. 24, no. 10, pp. 807 - 813, 2002.

[41] V. S. C. Lim, J. D. F. McDonald, and T. K. Saha, "Development of a new loss allocation method for a hybrid electricity market using graph theory," Electric Power Systems Research, vol. 79, no. 2, pp. 301 - 310, 2009. https://doi.org/10.1016/j.epsr.2008.06.018

[42] C.T. Su and J.H. Liaw, "Complex power flow tracing considering convection lines using nominal-T model," International Journal of Electrical Power and Energy Systems, vol. 29, no. 1, pp. 28 - 35, 2007.

[43] Y. A. Alturki and K. L. Lo, "Real and reactive power loss allocation in pool based electricity markets," International Journal of Electrical Power and Energy Systems, vol. 32, no. 4, pp. 262 - 270, 2010.

[44] A. Parastar, B. Mozafari, A. Pirayesh, and H. Omidi, "Transmission loss allocation through modified Z-bus," Energy Conversion and Management, vol. 52, no. 1, pp. 752 - 756, 2011.

[45] K. Xie, J. Zhou, and W. Li, "Analytical model and algorithm for tracing active power flow based on extended incidence matrix," Electric Power Systems Research, vol. 79, no. 2, pp. 399 - 405, 2009. https://doi.org/10.1016/j.epsr.2008.08.001

[46] R. Haque and N. Chowdhury, "An artificial neural network based transmission loss allocation for bilateral contracts," in the Canadian Conference on
Electrical and Computer Engineering, 2005, pp. 2203 - 2207.

[47] N. B. Dev Choudhury and S. K. Goswami, "Artificial intelligence solution to transmission loss allocation problem," Expert Systems with Applications, vol. 38, no. 4, pp. 3757 - 3764, 2011. https://doi.org/10.1016/j.eswa.2010.09.035

\section{APPENDIX - Nomenclature}

\begin{tabular}{|c|c|}
\hline$P_{i-j}^{\text {gross }}$ & : Gross line flow on line $i-j$ \\
\hline$D_{i-j, k}^{\text {gross }}$ & $\begin{array}{l}\text { Contribution fraction in gross flow by } k \text {-th } \\
\text { generator }\end{array}$ \\
\hline$P_{G k}$ & : Generated power of $k$-th generator \\
\hline$P_{D i}^{\text {gross }}$ & : Gross load power \\
\hline$D_{D i, k}^{\text {gross }}$ & $\begin{array}{l}\text { Contribution fraction in gross load by } k \text {-th } \\
\text { generator }\end{array}$ \\
\hline $\mathbf{A}_{\mathbf{u}}$ & : Upstream matrix \\
\hline$P_{i-j}$ & : $\quad$ Line flow along line $i-j$ \\
\hline$P_{i}$ & : Total flow at bus $i$ \\
\hline$P_{D i}$ & : Load power at bus $i$ \\
\hline$\left[\mathbf{A}_{\mathbf{u}}\right]$ & : Element of upstream matrix \\
\hline$P_{l}^{k}$ & $\begin{array}{l}\text { Total losses allocated to } k \text {-th participant (load } \\
\text { / generator) }\end{array}$ \\
\hline$C_{o u t, k}^{i}$ & : Relative contribution \\
\hline$P_{j k}^{i}$ & : Absolute contribution \\
\hline$P_{i n, k}$ & : Total inflow \\
\hline$I_{G k}$ & : Injected current by generator \\
\hline$Z_{D i}$ & : Equivalent load impedance \\
\hline$P_{G k}$ & : Real power of generator \\
\hline$Q_{G k}$ & : Reactive power of generator \\
\hline$V_{G k}$ & : Generator's voltage \\
\hline$V_{i}^{k}$ & : Contributed voltage by generator \\
\hline$I_{i j}^{k}, I_{D i}^{k}$ & $\begin{array}{l}\text { Contributed line current and load current by } \\
\text { generator }\end{array}$ \\
\hline$S_{i j}^{k}, S_{D}^{k}$ & $\begin{array}{l}\text { Contributed complex line flow and load power } \\
\text { by generator }\end{array}$ \\
\hline$S_{\text {loss }}^{k}$ & : Contributed complex losses by generator \\
\hline$\beta_{f l}^{k}$ & Contributed line flow fraction by generator \\
\hline & Contributed load power fraction by generator \\
\hline$\beta_{\text {loss }}^{k}$ & Contributed losses fraction by generator \\
\hline$N_{G}$ & Number of generators \\
\hline$N_{D}$ & Number of loads \\
\hline$N_{L}$ & Number of lines \\
\hline $\mathbf{S}_{\mathrm{GT}}$ & : Decision variable matrix \\
\hline$P_{f l}$ & : Line flow \\
\hline$P_{l o s s}^{k}$ & : Contributed loss by generator \\
\hline$P_{s l}^{l o s s,}$ & : Sending end power \\
\hline$P_{r l}$ & : Receiving end power \\
\hline
\end{tabular}

